\title{
COMMUNICATION
}

\section{Interview with David Goldberg}

\author{
Harriet Pollatsek
}

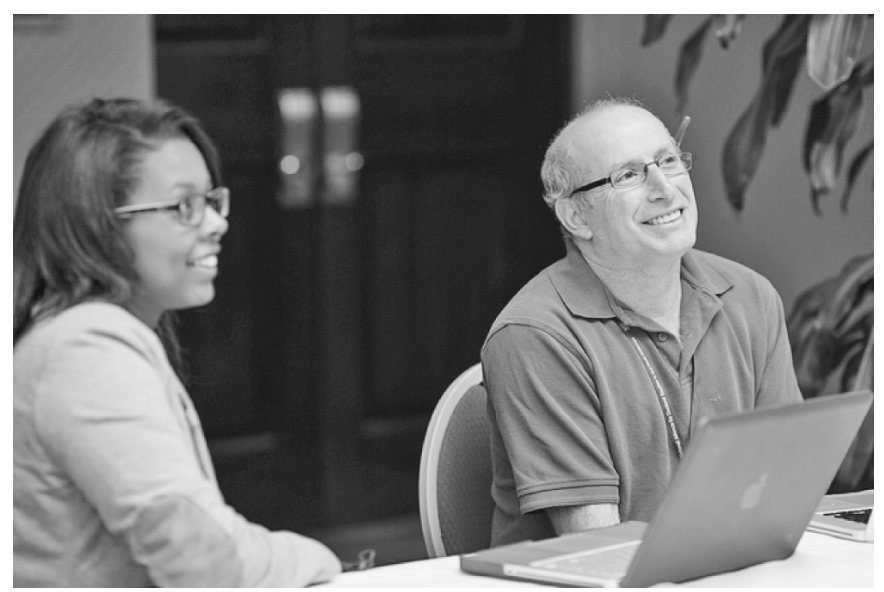

David Goldberg, new executive director of the National Alliance for Graduate Studies, with Jasmine Jackson at the 2013 Field of Dreams

Conference. Goldberg mentored Jackson in the Uniform Admissions Process. She is now at Arizona State in the Applied Mathematics for the Life and Social Sciences Program.

In March 2016 the National Alliance for Doctoral Studies in the Mathematical Sciences, a program which until then had been housed at the University of Iowa, moved

David Goldberg is professor of mathematics and associate head of graduate studies at Purdue University. He is soon to be executive director of the National Alliance for Doctoral Studies in the Mathematical Sciences. His email address is goldberg@ math. purdue.edu.

Harriet Pollatsek is professor emerita of mathematics at Mount Holyoke College and a member of the Notices editorial board. Her email address is hpo11ats@mtholyoke.edu.

For permission to reprint this article, please contact:

reprint-permission@ams.org.

DOI: http://dx.doi.org/10.1090/noti1410 to Purdue University; David Goldberg assumed the role of executive director. This interview was conducted via email.

Pollatsek: What is the National Alliance and what does it do?

Goldberg: The Alliance is a community of faculty devoted to increasing the number of students from backgrounds traditionally underrepresented in the mathematical sciences who earn PhDs in those fields. It is a cooperative effort by graduate programs (GPGs) and faculty at many campuses, ranging from four-year colleges to doctoral-granting institutions, attempting to ensure that any US student with the talent and desire can earn a doctorate. Through the Alliance mentoring programs, we try to make sure each student enrolls and succeeds in a program that suits his or her goals, ambitions, and preparation.

Currently there are two main activities of the Alliance. The first is what we call the Facilitated Graduate Admissions Process, or F-GAP, where undergraduates in their junior year are paired with a faculty mentor at a doctoralgranting department. The student, the doctoral faculty mentor, and the student's undergraduate faculty mentor work together to help the student prepare graduate school applications. So, they might discuss what courses the student should plan to take, what REU opportunities best suit the student, and try to figure out which are the best programs for the student to apply to. They also work on the student's résumé and personal statement.

The second major Alliance activity is the annual Field of Dreams Conference. This brings together about two hundred students and about one hundred faculty for three days. During this time several things happen. There are panels for students on topics to help them prepare for and apply to graduate school. There are panels for faculty members regarding best practices for mentoring and for young faculty centering on career development. There are several opportunities for F-GAP students and 
mentors to meet one-on-one to finalize the student's application materials. There is a graduate school fair featuring most of the GPGs, and several other graduate programs and institutional exhibitors come as well. There are also keynote speakers and scientific speakers. People can learn more about the Field of Dreams Conference at the Alliance website.

Pollatsek: Approximately how many students have participated in F-GAP? Thus far, what can you say about outcomes?

Goldberg: As a little background, there was a precursor to F-GAP which was called the Uniform Admissions Process (UAP), and that was run in the fall of 2013. That year we placed 61 students in graduate programs for fall 2014 (48 in PhD programs, 13 in MS or postbac programs). F-GAP started the following spring and placed 65 students in graduate programs for fall 2015 (53 in PhD programs and 12 in MS programs). This past year we had 94 students participate in F-GAP, and this is the time when they will learn the outcome of their applications. We recently surveyed the students from UAP and F-GAP over the past two years to see what their current status is. For the first group we received responses from 55 of the 61 participants, and 52 of those are in their second year of the graduate program they were placed in. One student has left the program, one student switched programs, and one finished an MS program and is working. For the second group, who enrolled in graduate school this past fall, we heard from 54 of the 65 participants, and 52 of them are still in their program, while 2 have left their program. I should point out that the students who participate in Alliance programs are about 80 percent underrepresented minorities, and the participants in FGAP roughly mirror those demographics. Of the three students who left their program within the first two years, one was an underrepresented minority student, while two were majority students.

Because the Alliance was staffed differently before 2012, we actually don't have precise data before that point, but since the Alliance has been around in some form since 2001, Alliance Scholars have been earning PhDs for about a decade. The Alliance began to expand towards its current form in 2006. At that time the percentage of US PhDs in the mathematical sciences being awarded to underrepresented minority students was about 6 percent, and it

\section{My long-term vision is that we get to a point where an organization like the Alliance is no longer necessary to guarantee talented students have access to opportunities in graduate education}

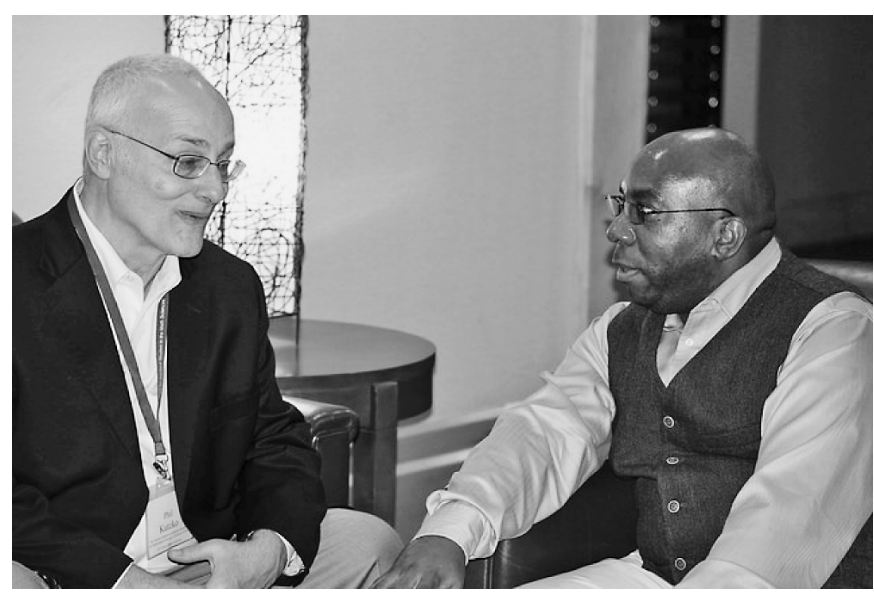

Phil Kutzko (left), director of the Math Alliance, talks with Edray Goins, incoming associate director at Purdue University.

had been even less in some years prior to that. As of 2012 it had risen to 8.5 percent. While the Alliance is not solely responsible for this significant increase, I think it is reasonable to infer that the Alliance is a factor. Now that we are keeping data, we will be better able to gauge the extent to which we are impacting the work force in our profession. We do know that at least 200 Alliance scholars are currently attending doctoral programs in the mathematical sciences, and 157 of them are in programs with an Alliance GPG. Over the past five years, approximately one third of all doctoral degrees in the mathematical sciences awarded to students from underrepresented groups were awarded by programs with an Alliance GPG. Also, the impact on the culture of graduate programs and our profession goes even further. The mentoring structures that are developed and implemented at GPGs are available to majority students as well, and these can improve the success rate for all students.

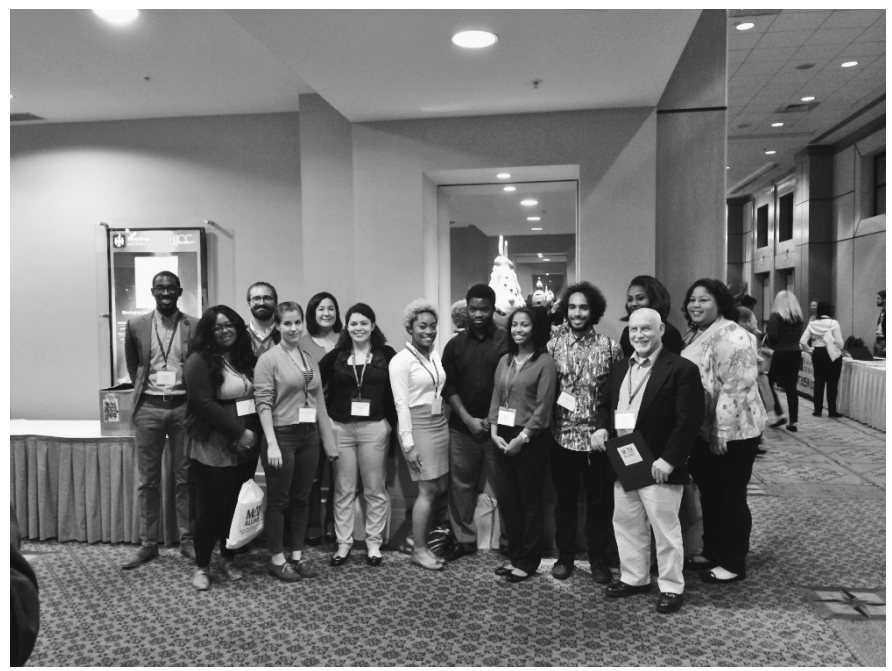

A group from Xavier University of New Orleans at the 2015 Field of Dreams Conference. 
Pollatsek: What are your goals for the National Alliance?

Goldberg: The Alliance has grown significantly in the last few years and is having tremendous success and impact. So, our initial goal is to maintain the activities and services of the Alliance, essentially in their present form. Since change in the Alliance comes through a process of community building, we need to keep that process going and help foster the growth of the Alliance in the way the community wants. My long-term vision is that we get to a point where an organization like the Alliance is no longer necessary to guarantee talented students have access to opportunities in graduate education.

Pollatsek: Do you intend any changes in emphasis or new initiatives?

Goldberg: Not really. The transition is really a change in how the Alliance is administered, but the activities and programs of the Alliance will continue in their present form. Again, change comes from the community, and our job at Purdue is to implement the policies and programs envisioned by the community. Since the Alliance is an evolving community, there will be some changes. For instance, Alliance doctoral mentors have indicated a desire to reach students a little earlier in their undergraduate programs, and we will help find ways to make that happen.

Pollatsek: What challenges do you anticipate?

Goldberg: The main challenge for me, personally, is to learn how to best serve the Alliance community, and I have a lot to learn. I am getting tremendous support from the current staff, the director, Phil Kutzko, and the broader community in this process. In fact, Professor Kutzko has agreed to remain as director for the next couple of years. I am also fortunate to have significant support from Purdue University, including the Department of Mathematics, the College of Science, the Graduate School, and the provost.

Organizationally, the main challenges right now are to hire staff and secure funding. There are two current staff at the University of Iowa (one full-time program manager and one half-time person who assists the program manager, handles the webpage, and does the data analysis). We need to find people who will learn the day-to-day operation of the Alliance from current staff and be able to carry on the work that is under way. The NSF has supported the Alliance as a pilot project for several years, but we now need to institutionalize the organization and find a way to pay our staff costs through other means. Purdue has agreed to provide staff support for a two-year transition period while we get such a funding model in place.

Pollatsek: What led you to this work?

Goldberg: The brief answer is I have had a long interest in seeing broader participation in our profession and have been fortunate to be close to some involved in the Alliance. Also, I was fortunate to be at Purdue, where our department's graduate program has evolved in large part due to the influence of the Alliance. So, as we transformed and eventually became a full-fledged GPG in the Alliance, we also became a natural candidate to be the new administrative home of the Alliance. So, a lot of it is being in the right place at the right time. Issues of

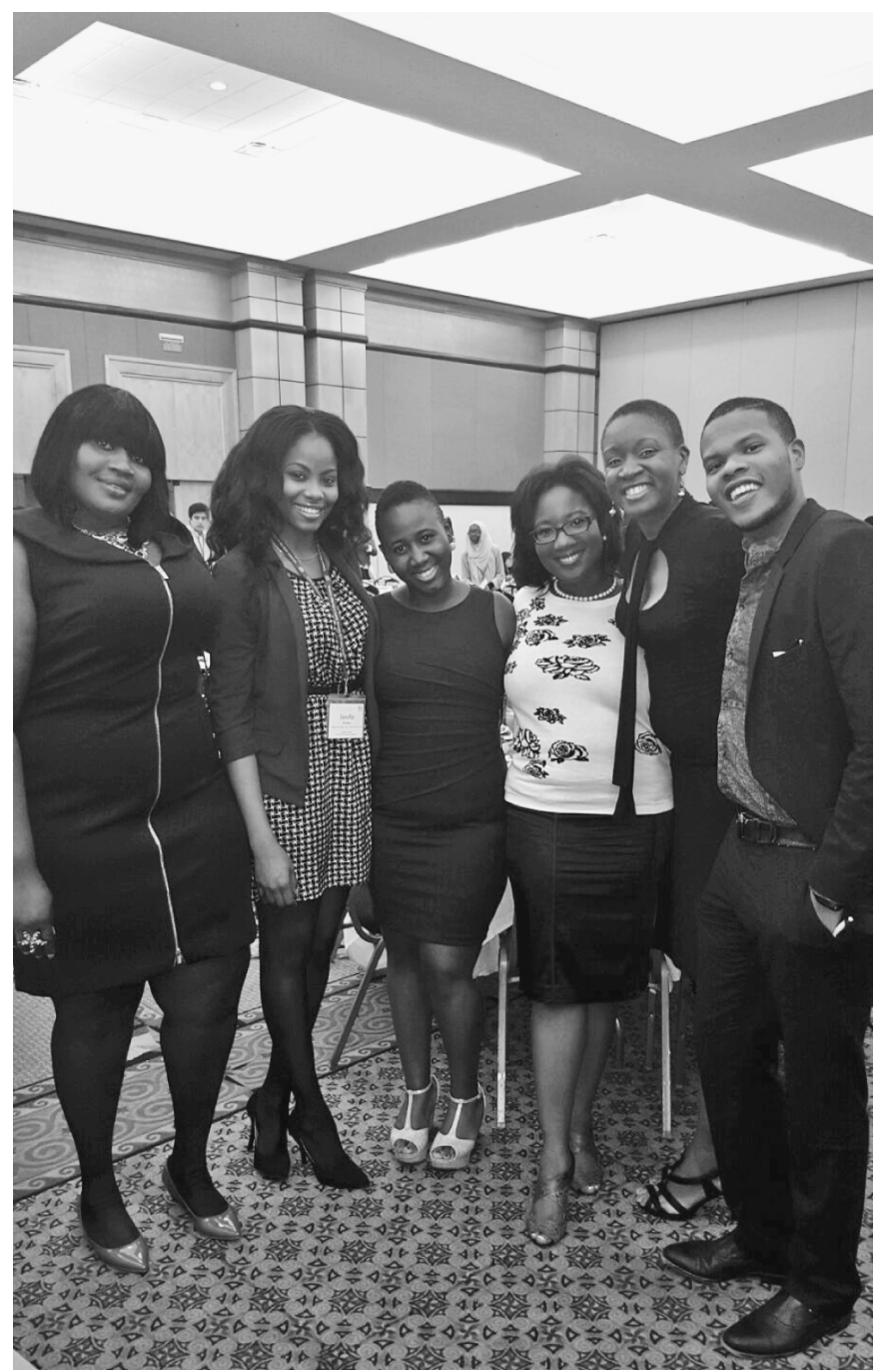

Keynote speaker Talithia Williams (third from right) of Harvey Mudd College with attendees at the 2015 Field of Dreams Conference.

equality, access, and inclusion are very much ingrained in me and have always been a priority. This is all rooted in my upbringing, my family, and a lot of early experiences.

\section{Credits}

Photo of David Goldberg, courtesy of Matt Le Photography. Photo of Phil Kutzko and Edray Goins, courtesy of

Dr. Donald Cole, University of Mississippi.

Photo of the 2015 Field of Dreams Conference, courtesy of Dr. Donald Cole, University of Mississippi.

Photo of Talithia Williams, courtesy of Janelle Walker, Alliance Scholar from Medgar Evers University. 